\title{
Mg Doping Effect on the Microstructural and Optical Properties of ZnO Nanocrystalline Films
}

\author{
San-Lin Young, ${ }^{1}$ Ming-Cheng Kao, ${ }^{1}$ Hone-Zern Chen, ${ }^{1}$ Neng-Fu Shih, \\ Chung-Yuan Kung, ${ }^{2}$ and Chun-Han Chen ${ }^{2}$ \\ ${ }^{1}$ Department of Electronic Engineering, Hsiuping University of Science and Technology, Taichung 41280, Taiwan \\ ${ }^{2}$ Department of Electrical Engineering, National Chung Hsing University, Taichung 40227, Taiwan
}

Correspondence should be addressed to San-Lin Young; slyoung@hust.edu.tw and Chung-Yuan Kung; cykung@nchu.edu.tw

Received 16 October 2014; Accepted 17 November 2014

Academic Editor: Changhong Ke

Copyright (C) 2015 San-Lin Young et al. This is an open access article distributed under the Creative Commons Attribution License, which permits unrestricted use, distribution, and reproduction in any medium, provided the original work is properly cited.

Transparent $\mathrm{Zn}_{1-x} \mathrm{Mg}_{x} \mathrm{O}(x=0.01,0.03$, and 0.05$)$ nanocrystalline films were prepared by sol-gel method followed by thermal annealing treatment of $700^{\circ} \mathrm{C}$. Mg doping effect on the microstructural and optical properties of the $\mathrm{Zn}_{1-x} \mathrm{Mg}_{x} \mathrm{O}$ films is investigated. From SEM images of all films, mean sizes of uniform spherical grains increase progressively. Pure wurtzite structure is obtained from the results of XRD. Grain sizes increase from $34.7 \mathrm{~nm}$ for $x=0.01$ and $37.9 \mathrm{~nm}$ for $x=0.03$ to $42.1 \mathrm{~nm}$ for $x=0.05$ deduced from the XRD patterns. The photoluminescence spectra of the films show a strong ultraviolet emission and a weak visible light emission peak. The enhancement of ultraviolet emission and reduction of visible emission are observed due to the increase of $\mathrm{Mg}$ doping concentration and the corresponding decrease of oxygen vacancy defects. Besides, the characteristics of the dark/photo currents with $n-\mathrm{Zn}_{1-x} \mathrm{Mg}_{x} \mathrm{O} / n$-Si heterojunction are studied for photodetector application.

\section{Introduction}

The $\mathrm{ZnO}$-based semiconductors have recently drawn much interest for the possible application in optoelectronics devices [1-3] due to the large direct band gap. These properties are important for application to commercial electronic products, such as photoconductors for electrophotography [4], varistors for electrical circuits [5], sensors for gas detection [6], and active layer for thin film transistors [7]. Highly conductive and optical transparent $\mathrm{ZnO}$ films in the visible range suitable for transparent electrodes in solar cell and liquid crystal display applications have been also reported $[8,9]$.

The $\mathrm{ZnO}$-based thin films have been fabricated through various methods [10-12]. However, sol-gel spin coating method offers more merits due to ease-control of chemical composition and simpler method for large area coating at a low cost, compared with other high vacuum fabrication processes. For the application of $\mathrm{ZnO}$-based semiconductors on electronic devices, one of the most promising methods is doping with elements from groups I and III and transitional metals [13-15]. While the shift in PL and XRD versus $\mathrm{Mg}$ composition has been studied previously [16, 17], it becomes interesting to further explore the doping effect on the microstructural and optical properties of the $\mathrm{ZnO}$ based films. In the present work, we survey the Mg-doping effect on the microstructural and optical properties of $\mathrm{ZnO}$ nanocrystalline films. In addition, the $I-V$ characteristics of photodetecting devices with $n-\mathrm{Zn}_{1-x} \mathrm{Mg}_{x} \mathrm{O} / n$-Si heterojunction are studied.

\section{Materials and Methods}

$\mathrm{Zn}_{1-x} \mathrm{Mg}_{x} \mathrm{O}(x=0.01,0.03$, and 0.05$)$ films were fabricated by sol-gel method. The source solutions were prepared by $\mathrm{Zn}\left(\mathrm{C}_{2} \mathrm{H}_{3} \mathrm{O}_{2}\right)_{2} \cdot 2 \mathrm{H}_{2} \mathrm{O}$ (zinc acetate dehydrate), $\mathrm{Mg}\left(\mathrm{CH}_{3} \mathrm{COO}\right)_{2} \cdot 4 \mathrm{H}_{2} \mathrm{O}$ (magnesium acetate), $\mathrm{C}_{3} \mathrm{H}_{8} \mathrm{O}_{2}$ (2methoxyethanol), and $\mathrm{C}_{2} \mathrm{H}_{7} \mathrm{NO}$ (ethanolamine). Zinc acetate dehydrate and magnesium acetate were firstly dissolved in 2 methoxyethanol in stoichiometric proportions. The concentration of metal ions was kept at $0.5 \mathrm{M}$. Then, ethanolamine 


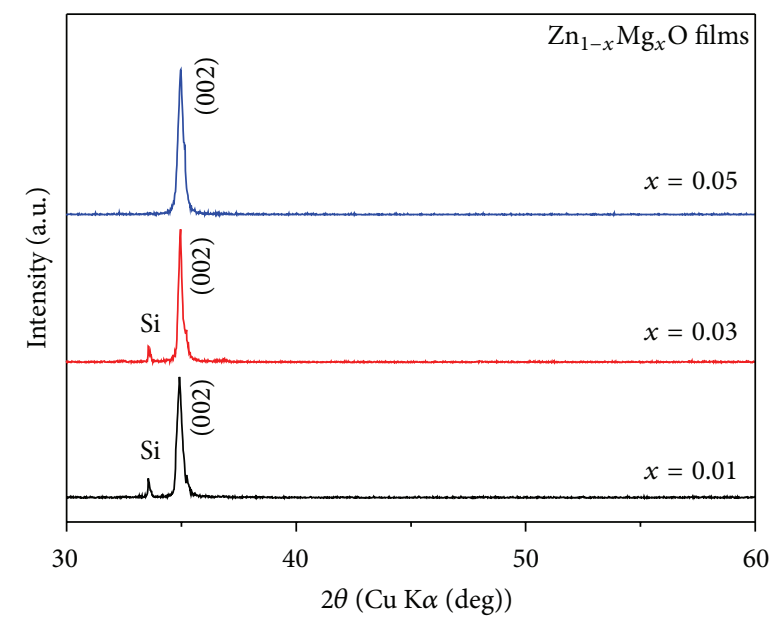

Figure 1: X-ray diffraction patterns of $\mathrm{Zn}_{1-x} \mathrm{Mg}_{x} \mathrm{O}$ films with $x=$ $0.01, x=0.03$, and $x=0.05$.

was added into the solutions to form stable precursor solutions. After stirring at $150^{\circ} \mathrm{C}$ for $1 \mathrm{~h}$ on a hotplate, transparent solutions were obtained. The $\mathrm{Zn}_{1-x} \mathrm{Mg}_{x} \mathrm{O}$ thin films were prepared by spin coating technique. Then, the samples were annealed by rapid thermal annealing treatment in air at the temperature of $700^{\circ} \mathrm{C}$ for $2 \mathrm{~min}$ with a heating rate of $600^{\circ} \mathrm{C} / \mathrm{min}$.

The crystal structure and grain orientation of $\mathrm{ZnO}$ films were determined by the X-ray diffraction (XRD) patterns using a Rigaku D/max 2200 X-ray diffractometer with $\mathrm{Cu}-\mathrm{K} \alpha$ radiation. The XRD data were recorded at room temperature under the $2 \theta$ range from $20^{\circ}$ to $60^{\circ}$ with a step width of $0.01^{\circ}$ and a scan speed of $0.5^{\circ} / \mathrm{min}$. Morphological characterization was observed using a field emission scanning electron microscopy (FE-SEM, JEOL JSM-6700F) at $3.0 \mathrm{kV}$. The transmittance spectra were obtained by JASCO V-670 spectrophotometer. Room temperature photoluminescence (PL) spectroscopy was applied for optical emission measurement from 330 to $645 \mathrm{~nm}$ and defect analysis using the $\mathrm{He}-\mathrm{Cd}$ laser with wavelength $325 \mathrm{~nm}$. Finally, the DC current-voltage $(I-V)$ characteristics of $\left(\mathrm{Zn}_{1-x} \mathrm{Mg}_{x} \mathrm{O}\right.$ film $) /(n$-Si substrate) structures were separately measured by an HP 4145 semiconductor parameter analyzer with the applied voltage from $-5 \mathrm{~V}$ to $5 \mathrm{~V}$ under darkness and photo illumination using a solar simulator with power density $1000 \mathrm{~W} / \mathrm{cm}^{2}$ as the irradiation source.

\section{Results and Discussion}

Figure 1 illustrates the XRD patterns of $\mathrm{Zn}_{1-x} \mathrm{Mg}_{x} \mathrm{O}$ nanocrystalline films. Based on the XRD patterns, all Mg-doped samples are found to have the same single polycrystalline phase with the wurtzite hexagonal structure of P63/mc. All samples exhibit the (002) preferred orientation, indicating $c$-axis orientation. The progressive narrowing of the XRD peaks with the increase of $\mathrm{Mg}$ concentration is related to the increase of the grain size of the nanocrystalline films. The average grain size of the samples, obtained by the classical Scherrer formula, increases gradually from $34.7 \mathrm{~nm}$ for $x=$ 0.01 and $37.9 \mathrm{~nm}$ for $x=0.03$ to $42.1 \mathrm{~nm}$ for $x=0.05$.

Figure 2 shows the surface morphology of FE-SEM images which reveals porously granular structure for all $\mathrm{Zn}_{1-x} \mathrm{Mg}_{x} \mathrm{O}$ films. It is clear that the grain size increases progressively with the increase of the $\mathrm{Mg}$ concentration, which is consistent with the results indicated in Figure 1. Furthermore, the film thickness decreases from $132 \mathrm{~nm}$ for $x=0.01$ and $124 \mathrm{~nm}$ for $x=0.03$ to $105 \mathrm{~nm}$ for $x=0.05$. It is for the reason that the film is gradually densified due to the increase of $\mathrm{Mg}$ doping concentration.

Figure 3 shows the PL spectra for all $\mathrm{Zn}_{1-x} \mathrm{Mg}_{x} \mathrm{O}$ films. Two distinct emissions including an obvious ultraviolet (UV) emission and a weak green-yellow visible emission are observed. The UV emission originates from the exciton recombination corresponding through an exciton-exciton collision process [18]. The green-yellow emission is induced from the recombination of a photogenerated hole with an electron that belongs to a singly ionized defect, such as oxygen vacancy [19]. Gradual blue shift of the UV luminescence from $369.8 \mathrm{~nm}$ for $x=0.01$ and $366.2 \mathrm{~nm}$ for $x=0.03$ to $362.6 \mathrm{~nm}$ for $x=0.05$ occurs with the increase of Mg doping concentration. Using the luminescence data, the band gaps, $3.35 \mathrm{eV}$ for $x=0.01,3.38 \mathrm{eV} \mathrm{nm}$ for $x=0.03$, and $3.41 \mathrm{eV}$ nm for $x=0.05$, are calculated. As the $\mathrm{Mg}$ concentration increased, the results indicate a linear increase in the band gap due to the higher band gap of $\mathrm{MgO}(7.8 \mathrm{eV})$ than that of $\mathrm{ZnO}(3.3 \mathrm{eV})$. The intensity of the ultraviolet emission is strongly dependent on the crystalline quality of $\mathrm{ZnO}$ films [20]. Besides, the decrease of visible emission with increasing $\mathrm{Mg}$ concentration indicates the decrease of intrinsic defects [21]. The enhancement of ultraviolet emission intensity $\left(I_{\mathrm{UV}}\right)$ and reduction of green-yellow visible emission $\left(I_{\mathrm{VIS}}\right)$ are observed due to the increase of $\mathrm{Mg}$ doping concentration and the corresponding decrease of oxygen vacancy defects. The ratio of the emission intensities of visible to UV emission (denoted as $I_{\mathrm{VIS}} / I_{\mathrm{UV}}$ ) shows a decrease from 0.0876 and 0.0595 to 0.0488 of $\mathrm{Zn}_{1-x} \mathrm{Mg}_{x} \mathrm{O}$ films for $x=0.01, x=0.03$, and $x=0.05$, respectively. The decrease of $I_{\mathrm{VIS}} / I_{\mathrm{UV}}$ ratio with increasing $\mathrm{Mg}$ concentration of $\mathrm{Zn}_{1-x} \mathrm{Mg}_{x} \mathrm{O}$ films shows a decrease of defects and an enhancement of crystallinity of the $\mathrm{ZnO}$ films, which is consistent with the result observed from XRD patterns.

Figure 4 shows the $I-V$ characteristics of $\mathrm{Zn}_{1-x} \mathrm{Mg}_{x} \mathrm{O}$ films deposited on $n$-type Si substrates for photodetector application, which was measured separately under dark (dark current, $I_{\text {dark }}$ ) and photo illumination (photo current, $I_{\text {photo }}$ ). The previous report elsewhere [22] stated that zinc oxides usually exhibit $n$-type semiconductor nature due to in situ defects. The PL results reveal the decrease of defects with $\mathrm{Mg}$ doping increase. We may continuously deduce the results of the decrease of carrier concentration, the increase of resistivity, and the decrease of both $I_{\text {dark }}$ and $I_{\text {photo }}$ currents. The measured $\left(I_{\text {dark }}, I_{\text {photo }}\right)$ at $5 \mathrm{~V}$ are $(4.12 \mu \mathrm{A}, 5.52 \mu \mathrm{A})$, $(4.02 \mu \mathrm{A}, 5.12 \mu \mathrm{A})$, and $(3.80 \mu \mathrm{A}, 4.84 \mu \mathrm{A})$ for $x=0.01, x=$ 0.03 , and $x=0.05$, respectively. The variation of UV photoinduced current defined as $\left(I_{\text {photo }}-I_{\text {dark }}\right) / I_{\text {dark }}$ decreases from 


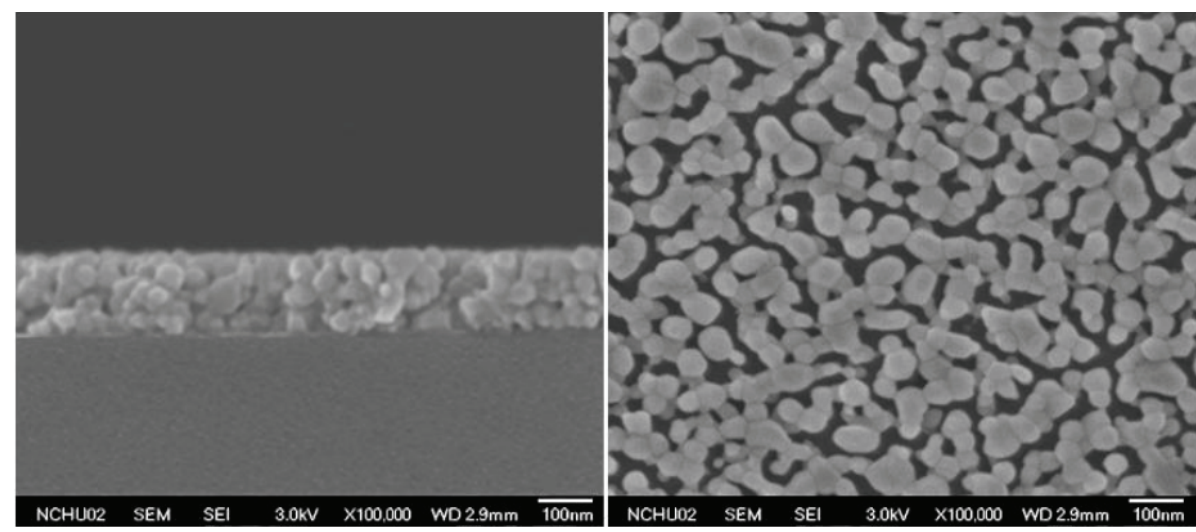

(a)

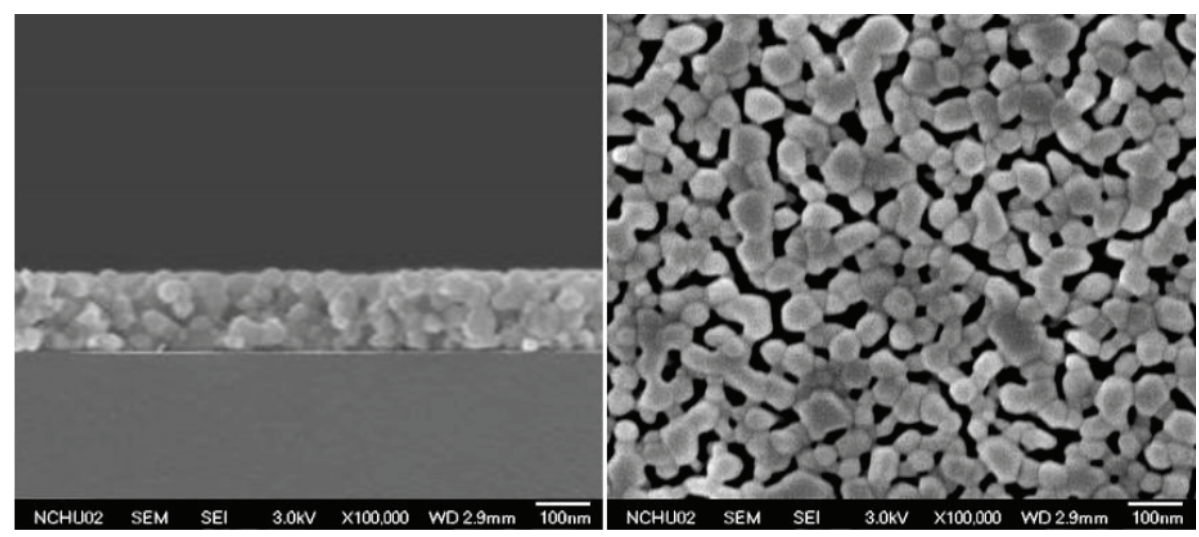

(b)

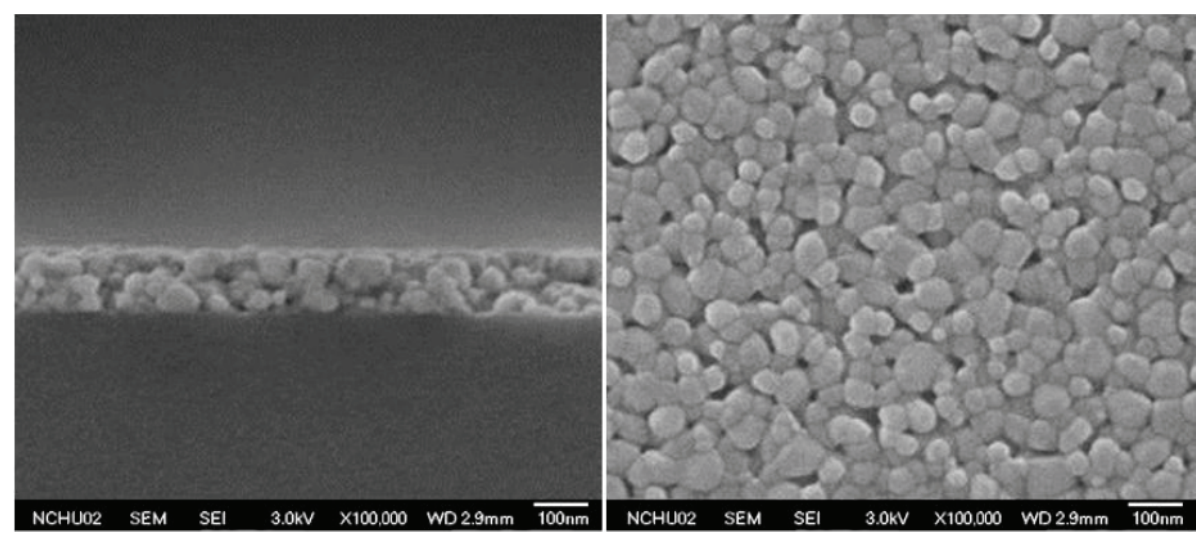

(c)

FIGURE 2: SEM images for $\mathrm{Zn}_{1-x} \mathrm{Mg}_{x} \mathrm{O}$ films of (a) $x=0.01$, (b) $x=0.03$, and (c) $x=0.05$. Left and right columns show the cross-section and top view, respectively. The scale bars denote $100 \mathrm{~nm}$.

$34 \%$ and $28 \%$ to $27 \%$. The results reveal the possibility of $\mathrm{ZnO}$-based semiconductors for photodetector application.

\section{Conclusions}

The Mg-doped $\mathrm{ZnO}$ nanocrystalline films were separately deposited by sol-gel spin coating method for comparison of microstructural and optical properties. XRD patterns show that all compositions are found to exhibit the same wurtzite hexagonal structure with group space P63/mc. FESEM images show the grain size increases and the thickness decreases of $\mathrm{Zn}_{1-x} \mathrm{Mg}_{x} \mathrm{O}$ films with the increase of $\mathrm{Mg}$ doping concentration. The results of photoluminescence spectra show a linear increase of band gap and a decrease of defects. $I-V$ curves with the dark and photo illumination of the $\mathrm{Zn}_{1-x} \mathrm{Mg}_{x} \mathrm{O}$ film/n-Si structures reveal the possibility of $\mathrm{ZnO}$-based semiconductors for photodetector application. 


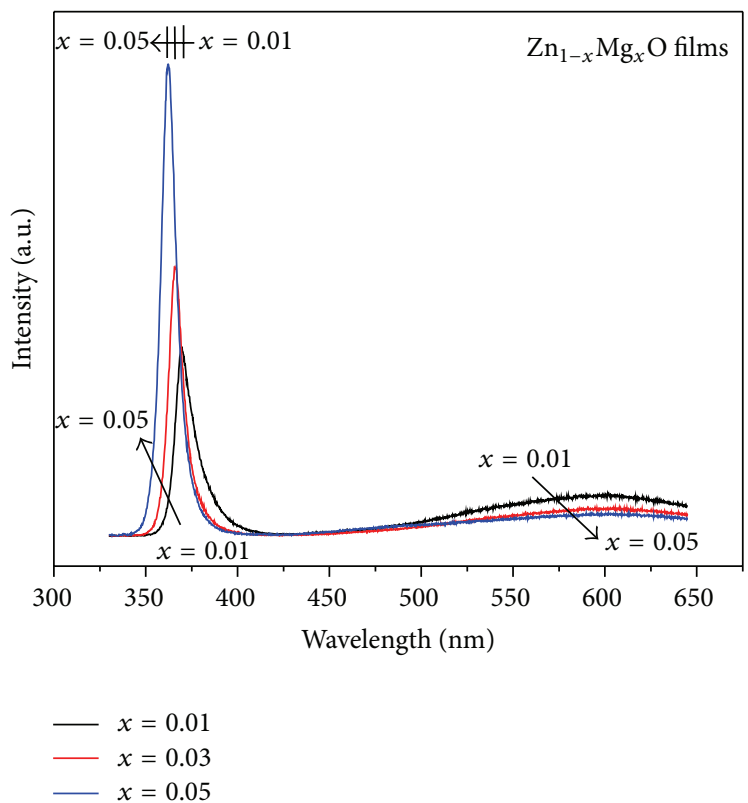

FIGURE 3: Photoluminescence spectra of $\mathrm{Zn}_{1-x} \mathrm{Mg}_{x} \mathrm{O}$ films with $x=0.01, x=0.03$, and $x=0.05$.
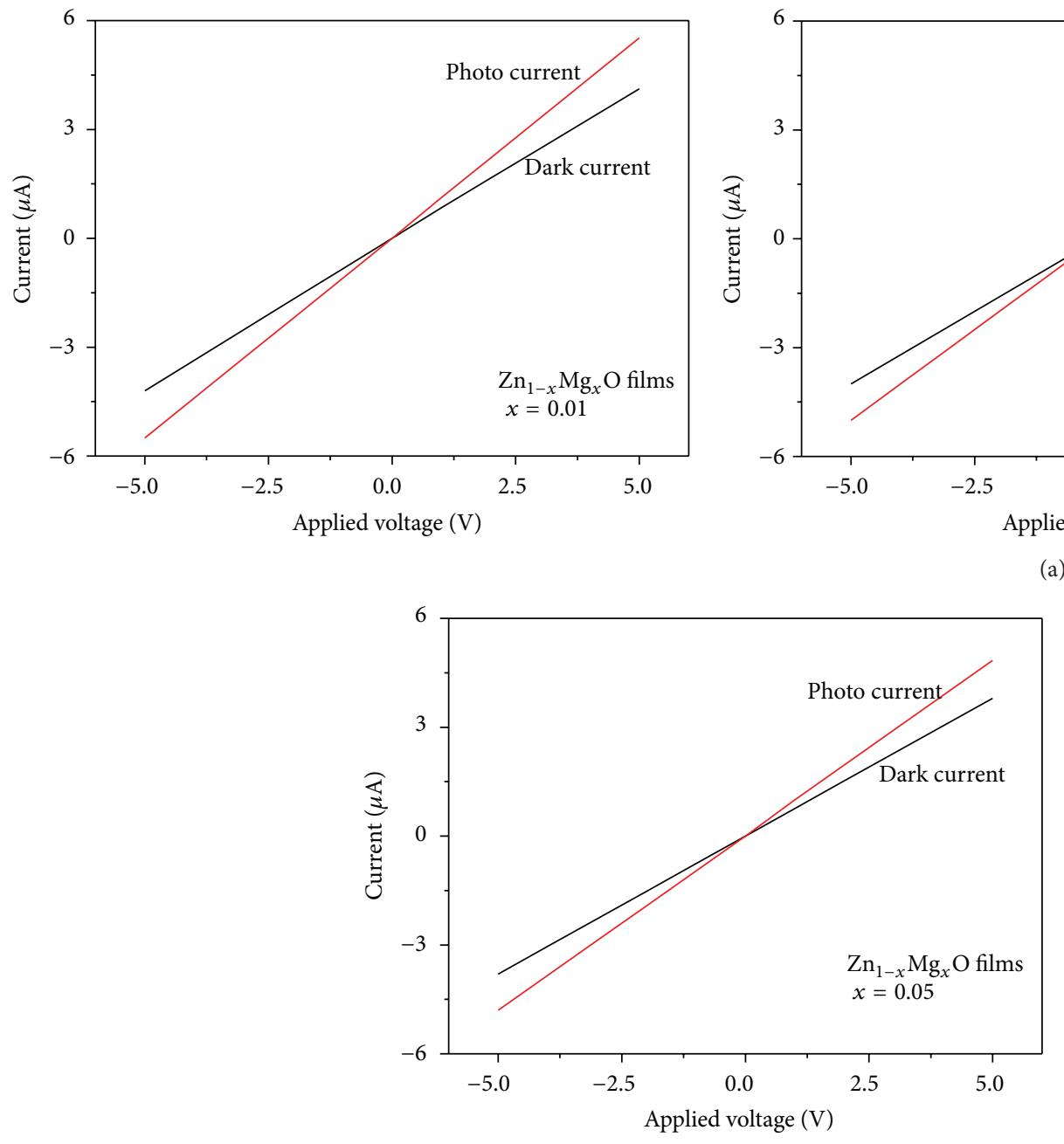

(b)

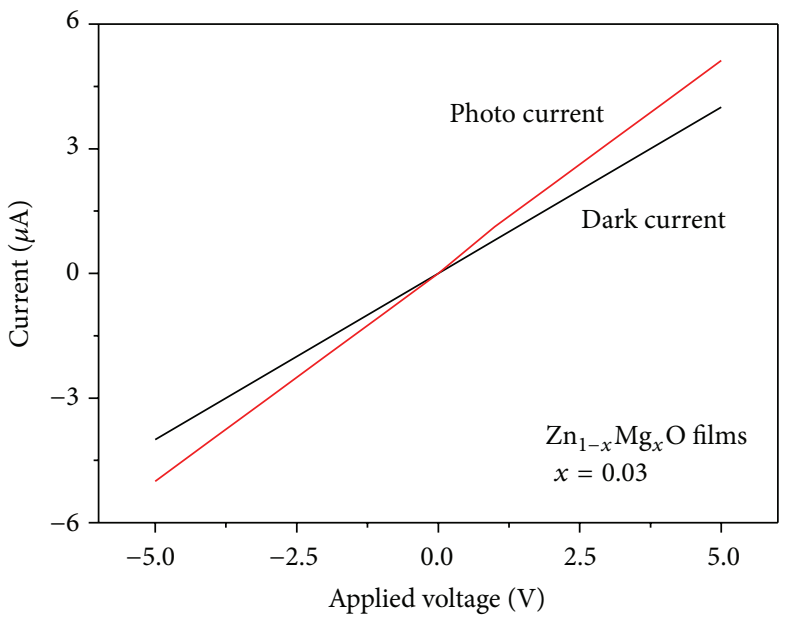

(a)

FIgURE 4: Dark/photo $I-V$ curves of $\mathrm{Zn}_{1-x} \mathrm{Mg}_{x} \mathrm{O}$ films with (a) $x=0.01$, (b) $x=0.03$, and (c) $x=0.05$. 


\section{Conflict of Interests}

The authors declare that there is no conflict of interests regarding the publication of this paper.

\section{Acknowledgment}

This work was sponsored by the Ministry of Science and Technology of the Republic of China under Grants nos. MOST 103-2221-E-164-003 and MOST 103-2221-E-005-033.

\section{References}

[1] P. I. Reyes, C.-J. Ku, Z. Duan, Y. Lu, A. Solanki, and K.-B. Lee, "ZnO thin film transistor immunosensor with high sensitivity and selectivity," Applied Physics Letters, vol. 98, no. 17, Article ID 173702, 2011.

[2] K. Liu, M. Sakurai, and M. Aono, "ZnO-based ultraviolet photodetectors," Sensors, vol. 10, no. 9, pp. 8604-8634, 2010.

[3] M. Ahmad and J. Zhu, " $\mathrm{ZnO}$ based advanced functional nanostructures: synthesis, properties and applications," Journal of Materials Chemistry, vol. 21, no. 3, pp. 599-614, 2011.

[4] K.-K. Kim, S. Niki, J.-Y. Oh et al., "High electron concentration and mobility in Al-doped $n-\mathrm{ZnO}$ epilayer achieved via dopant activation using rapid-thermal annealing," Journal of Applied Physics, vol. 97, no. 6, Article ID 066103, 2005.

[5] A. Sedky, T. A. El-Brolossy, and S. B. Mohamed, "Correlation between sintering temperature and properties of $\mathrm{ZnO}$ ceramic varistors," Journal of Physics and Chemistry of Solids, vol. 73, no. 3, pp. 505-510, 2012.

[6] S. Öztürk, N. Kilinç, N. Taşaltin, and Z. Z. Öztürk, "A comparative study on the $\mathrm{NO}_{2}$ gas sensing properties of $\mathrm{ZnO}$ thin films, nanowires and nanorods," Thin Solid Films, vol. 520, no. 3, pp. 932-938, 2011.

[7] A. Alias, K. Hazawa, N. Kawashima, H. Fukuda, and K. Uesugi, "Fabrication of zno thin-film transistors by chemical vapor deposition method," Japanese Journal of Applied Physics, vol. 50, no. 1, Article ID 01BG05, 2011.

[8] N. Hirahara, B. Onwona-Agyeman, and M. Nakao, "Preparation of Al-doped $\mathrm{ZnO}$ thin films as transparent conductive substrate in dye-sensitized solar cell," Thin Solid Films, vol. 520, no. 6, pp. 2123-2127, 2012.

[9] N. Yamamoto, H. Makino, Y. Hirashima et al., "Heat resistance of Ga-doped $\mathrm{ZnO}$ thin films for application as transparent electrodes in liquid crystal displays," Journal of the Electrochemical Society, vol. 157, no. 2, pp. J13-J20, 2010.

[10] S. Agrawal, R. Rane, and S. Mukherjee, "ZnO thin film deposition for TCO application in solar cell," Conference Papers in Energy, vol. 2013, Article ID 718692, 7 pages, 2013.

[11] W. L. Dang, Y. Q. Fu, J. K. Luo, A. J. Flewitt, and W. I. Milne, "Deposition and characterization of sputtered $\mathrm{ZnO}$ films," Superlattices and Microstructures, vol. 42, no. 1-6, pp. 89-93, 2007.

[12] C.-Y. Tsay, H.-C. Cheng, Y.-T. Tung, W.-H. Tuan, and C.-K. Lin, "Effect of Sn-doped on microstructural and optical properties of ZnO thin films deposited by sol-gel method," Thin Solid Films, vol. 517, no. 3, pp. 1032-1036, 2008.

[13] S. H. Jeong, B. N. Park, S.-B. Lee, and J.-H. Boo, "Study on the doping effect of Li-doped $\mathrm{ZnO}$ film," Thin Solid Films, vol. 516, no. 16 , pp. 5586-5589, 2008.
[14] Y. Liu, Y. Li, and H. Zeng, "ZnO-based transparent conductive thin films: doping, performance, and processing," Journal of Nanomaterials, vol. 2013, Article ID 196521, 9 pages, 2013.

[15] C. C. Lin, S. L. Young, C. Y. Kung et al., "Effect of Fe doping on the microstructure and electrical properties of transparent $\mathrm{ZnO}$ nanocrystalline films," Thin Solid Films, vol. 529, pp. 479-482, 2013.

[16] J. Huso, J. L. Morrison, H. Hoeck et al., "Pressure response of the ultraviolet photoluminescence of $\mathrm{ZnO}$ and $\mathrm{MgZnO}$ nanocrystallites," Applied Physics Letters, vol. 89, no. 17, Article ID 171909, 2006.

[17] K. K. Zhuravlev, W. M. Hlaing Oo, M. D. McCluskey, J. Huso, J. L. Morrison, and L. Bergman, "X-ray diffraction of $\mathrm{Mg}_{x} \mathrm{Zn}_{1-x} \mathrm{O}$ and $\mathrm{ZnO}$ nanocrystals under high pressure," Journal of Applied Physics, vol. 106, Article ID 013511, 2009.

[18] D. Banerjee, J. Y. Lao, D. Z. Wang et al., "Synthesis and photoluminescence studies on $\mathrm{ZnO}$ nanowires," Nanotechnology, vol. 15, no. 3, pp. 404-409, 2004.

[19] B. Lin, Z. Fu, and Y. Jia, "Green luminescent center in undoped zinc oxide films deposited on silicon substrates," Applied Physics Letters, vol. 79, no. 7, pp. 943-945, 2001.

[20] G. Kenanakis, M. Androulidaki, D. Vernardou, N. Katsarakis, and E. Koudoumas, "Photoluminescence study of $\mathrm{ZnO}$ structures grown by aqueous chemical growth," Thin Solid Films, vol. 520, no. 4, pp. 1353-1357, 2011.

[21] K. W. Liu, R. Chen, G. Z. Xing, T. Wu, and H. D. Sun, "Photoluminescence characteristics of high quality $\mathrm{ZnO}$ nanowires and its enhancement by polymer covering," Applied Physics Letters, vol. 96, no. 2, Article ID 023111, 2010.

[22] M. D. McCluskey and S. J. Jokela, "Defects in ZnO,” Journal of Applied Physics, vol. 106, no. 7, Article ID 071101, 2009. 

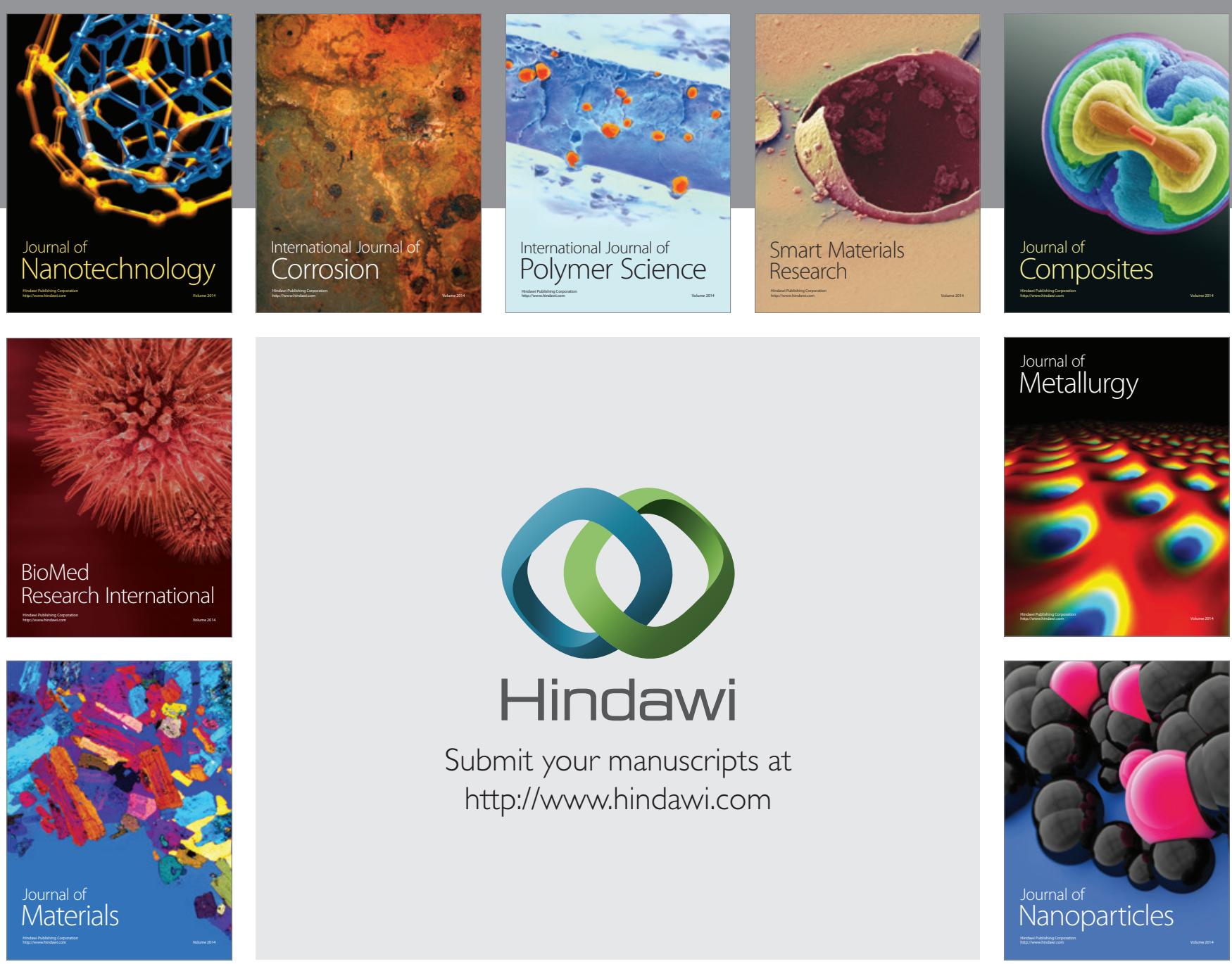

Submit your manuscripts at http://www.hindawi.com
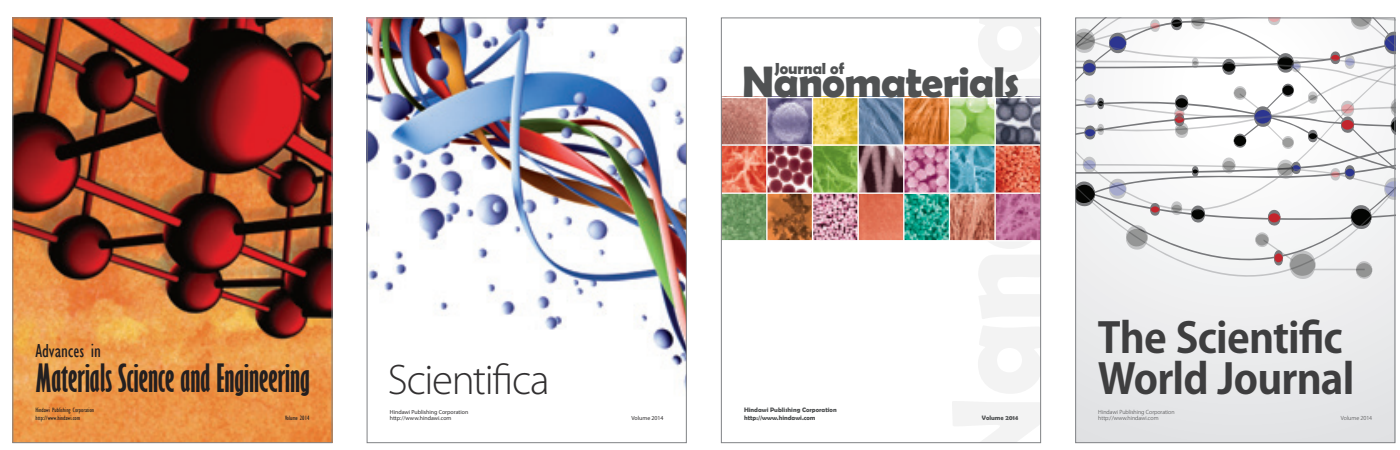

\section{The Scientific World Journal}
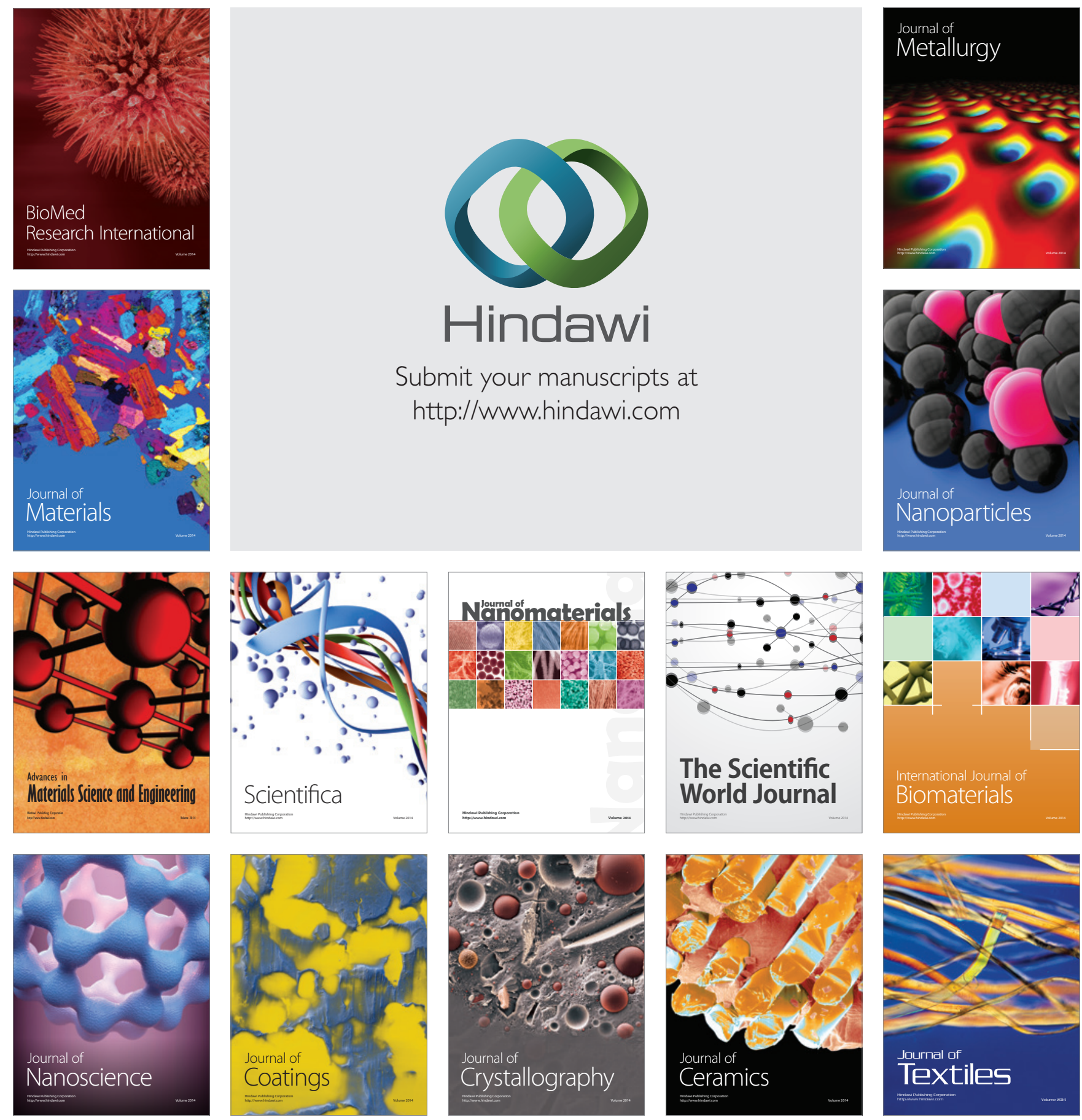